\title{
Histological architecture of cardiac myofibers composing the left ventricle of murine heart
}

Zienab A. Gouda ${ }^{1 \dagger}$, Yaser Hosny Ali Elewa ${ }^{2^{* \dagger}}$ and Assmaa O. Selim ${ }^{1}$

*Correspondence: yaserelewa@zu.edu.eg

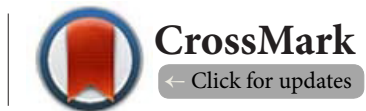

${ }^{\dagger}$ These authors contributed equally to this work.

'Department of Histology and Cell Biology, Faculty of Medicine, Zagazig University, Zagazig 44519, Egypt.

${ }^{2}$ Department of Histology and Cytology, Faculty of Veterinary Medicine, Zagazig University, Zagazig 44519, Egypt.

\begin{abstract}
Background: Despite the fact that the exact architecture and orientation of left ventricular myocardial fibers are critical to cardiac functions either in health or disease, it is still debated.

Aim of the work: Histological demonstration of the transverse alignment of the myofibers making the left ventricular mass was applied to validate different anatomical speculations of cardiac myofibers organization; mainly Streeter's conjecture and the ventricular myocardial band model of Torrent-Guasp.

Material and methods: Six healthy adult male C57BL/6N mice were utilized. Their hearts were separated into atria and ventricles. Then, both ventricles were divided into four levels [base, upper mid, lower mid and apex]. Paraffin step-serial transverse sections were stained with H\&E and Masson's trichrome stains. Morphometrical measurements of the thickness of the anterior, posterior, and lateral walls of the left ventricle (LV) as well as the inter-ventricular septal wall were realized with ImageJ software. For data analyses among the four levels of LV, Scheffé's method was applied for multiple comparisons when a significant difference was observed by Kruskal-Wallis test $(p<0.05)$.

Results: Examination of the LV from its base to its apex revealed obvious changes in the thickness of its walls and inter-ventricular septum as well as in its cavity shape. Interestingly, the myocardial fibers showed different running patterns [longitudinal, oblique and circular] among different levels as well as within the same level from sub-epicardial to the endocardial region. Throughout all levels, the subepicardial myofibers showed longitudinal orientation while that of the intermediate wall revealed either oblique [in upper mid-level] or circular orientations in other levels. The sub-endocardial fibers were mostly longitudinal with the presence of some circular fibers in the base and upper-mid regions. Masson's trichrome sections revealed a trivial amount of collagen fibers just around each individual myocyte without any bundle formation.
\end{abstract}

Conclusion: The presence of different running patterns of the myocardial fibers among different levels of LV as well as within the same level indicates multiple rolling of the myocardial fibers. Thus, we suggested that the band model by Torrent-Guasp accounts for the patterns of myocardial fiber architecture forming the left ventricle.

Keywords: Left ventricle, myocardial band, Torrent-Guasp, C57BL/6N mice

\section{Introduction}

The structure and function of organs are inseparable both in health and disease states. Many questions in cardiovascular medicine are still pending due to the insufficient insight in the basic science [1]. In particular, the elucidation of left ventricular myocardial architecture is critical to understand the exact mechanisms of cardiac functions. The cardiac myofibers orientation plays an important role not only in mechanical contraction but also in the electrical conduction and energy metabolism [2]. Although there are numerous anatomical works 
Gouda et al. Journal of Histology \& Histopathology 2015,

http://www.hoajonline.com/journals/pdf/2055-091X-2-2.pdf

doi: $10.7243 / 2055-091 X-2-2$

concerned with dissection of the musculature of the heart, this topic has received little histological details attention over the past 20 years [3].

Many anatomical speculations had been documented about the exact ventricular myocardial arrangement. The organization of cardiac myofibers as following: "Myocardial fibers run like geodesics on a nested set of toroidal bodies of revolution" was described [4]. Further investigation showed that the musculature of the heart is arranged on the basis of a modified blood vessel rather than in the fashion of a skeletal muscle which has discrete origin and insertion [5]. The heart was described as a muscular band that begins in the insertion of the pulmonary artery and ends at the level of the aorta, forming a double helix, which limits both ventricles [6]. It is noteworthy, however, that although Torrent-Guasp [6] also de-emphasized the concept of the fibrous skeleton as a potential anchorage of the fibers, he offered no explanation as to the nature of the anatomical structures which permitted him to dissect out the myocardial band with the consistency he claimed to demonstrate [7].

Recently, by blunt dissection of the epicardium, or epimysium, that surrounds the ventricular mass, the cardiac myofibers forming the left ventricle (LV) had been reported to be organized in branching layers separated by cleavages, referred to as the "sheet architecture" $[\mathbf{8 , 9}]$.

By using diffusion tensor magnetic resonance imaging on the ventricular epicardium, the fibers are shown to extend obliquely. While, in the middle layer of the anterior, the posterior and lateral walls of the left ventricle, the fibers are nearly circumferential. In the endocardium, the fiber orientation is more oblique on the anterior wall than the posterior wall. Finally, from the apex to the base of the heart, the epicardial fibers are arranged clockwise, and the endocardial fibers are counter-clockwise [2].

There is no anatomic evidence supporting the concept of the "ventricular myocardial band" [7]. Moreover, previous histological studies that described the ventricular myocardium were very shallow as most studies use cross-sectional or longitudinal areas of one level only. Transversally, the myocardium wall is made up of millions of myocytes set in a matrix of connective tissue. Each individual cardiac myocyte appears as a long thin cell, possessing multiple side branches, joined to its neighbors by intercalated discs [10]. Longitudinally, the myofibers in subendocardial and subepicardial parts of the LV wall run parallel to the ventricular equator [5].

The previous histological data concerning the architecture and orientation of cardiac myofibers in the LV are scarce. Furthermore, the previously mentioned anatomical speculations of the cardiac myofibers organization remain a highly contentious topic and have not yet been histologically confirmed.

Thus the aim of the present study was to validate different anatomical speculations of cardiac myofibers organization by histological examination of step-serial transverse sections over all the different levels of murine LV. We hypothesized that the observation of the running patterns of the cardiac myofibers in mouse LV at different levels could clarify the exact cardiac myofibers organization. In this study, we expected the presence of different running patterns of the myocardial fibers among different levels of $L V$ which could be an indication of the existence of multiple rolling and helical arrangements of cardiac myofibers.

\section{Material and methods}

\section{Animal and tissue preparation}

Six healthy adult male mice, eight to ten weeks old were purchased from Japan SLC [Shizuoka, Hamamatsu, Japan]. These animals were maintained in a controlled environment [room temperature of $22 \pm 4^{\circ} \mathrm{C}$, a relative humidity of $55 \pm 20 \%$, and a 12-h light and dark cycle] in the animal facility of the Graduate School of Veterinary Medicine, Hokkaido University. The mice were allowed free access to tap water and an adequate diet and were used at 4 months of age. In handling the experimental animals, the investigators adhered to the Guide for the Care and Use of Laboratory Animals, Hokkaido University, Graduate School of Veterinary Medicine [approved by the Association for Assessment and Accreditation of Laboratory Animal Care International].

After the mice had been killed by deep inhalation anesthesia, hearts were removed. The atria were separated from ventricles, and the total length of both ventricles was measured [average, $10 \mathrm{~mm}$ ]. Then, as there are variations in the septal wall thickness and the size of left ventricular cavity, we divided both ventricles transversally into four levels of equal thickness [average, 2.5 $\mathrm{mm}$ each]. The first level started just beneath the atria and characterized by narrow cavity and we considered it as "base level". The second and third parts were "upper and lower mid levels" characterized by wide cavity and thick septal wall and it represented the middle levels of the ventricles. The fourth cone-shaped level was characterized by narrow slit shaped cavity and thicker septal wall, and it represented "apex level".

Then, the cardiac tissues at four levels were fixed with $4 \%$ paraformaldehyde. For histological examination, the specimens were dehydrated in graded alcohol and embedded in paraffin. Subsequently, step serial sections [3- $\mu$ m-thickness] from different levels of the ventricles with $15 \mu \mathrm{m}$ interval after every 10 serial sections were cut. These sections were deparafinized, rehydrated rehydrated, stained with Hematoxylin and Eosin [H\&E] or Masson's trichrome [MT], and observed under light microscope [11].

\section{Morphometric study}

By using Image J software [National Institute of Health; $\mathrm{NIH}$, Bethesda, MD, USA], the thickness of the anterior, posterior, and lateral walls of the LV as well as the inter-ventricular septal wall was measured, analyzed, and compared among the four levels of heart [base, upper and lower mid and apex].

To measure the thicknesses of LV walls and inter-ventricular 
septum, we draw two lines; the first line was extended from epicardium of lateral LV to endocardium of right ventricle at the portion showing maximum lengths. The second line was extended from epicardium of anterior wall to that of posterior wall. This line was drawn at right angle to the first one. Then, to quantify the thickness of anterior and posterior walls, we measured the maximum lengths parallel to the first line extending from epicardium to endocardium at anterior and posterior regions of LV by using Image J software [NIH], respectively. Furthermore, to quantify the thickness of lateral ventricular wall and inter-ventricular septal wall, we measured the maximum lengths parallel to the second line extending from epicardium to endocardium at lateral regions of LV and extending from endocardium of LV to that of right ventricle by using Image J software [NIH], respectively.

\section{Statistical analysis}

All numerical results are shown as the mean \pm standard error [SE]. The results at the various levels were compared by using Kruskal-Wallis test and Scheffé's method for multiple comparisons when a significant difference was observed $[P<0.05]$.

\section{Results}

\section{$H$ and $E$ stained sections}

Histological features of $L V$ at different levels in mouse heart The mouse heart was divided into four main levels: base, upper mid, lower mid, and apex levels (Figure 1A). Step-serial $\mathrm{HE}$ stained cross sections of the LV revealed obvious changes in the thickness of anterior, lateral, posterior ventricular walls and inter-ventricular septum, as well as, in the shape of cavity among different levels of the heart. The results of histoplanimetrical analysis were summarized in (Table 1). Briefly, the anterior wall was the thickest at the base level [383.68 $\pm 0.29 \mu \mathrm{m}$ ] (Figure 1B). Then, it became gradually thinner towards the apex level [89.45 $\pm 0.78 \mu \mathrm{m}]$ (Figure 1E). The lateral ventricular wall was the thickest at the upper mid level [189.03 $\pm 0.58 \mu \mathrm{m}$ ] (Figure 1C), and it was the thinnest at the apex [93.32 $\pm 1.35 \mu \mathrm{m}]$ (Figure 1E). At the base level, the lowest thickness of posterior wall [64.68 $\pm 0.23 \mu \mathrm{m}]$ and inter-ventricular septal wall [135.89 $\pm 0.55 \mu \mathrm{m}]$ was observed (Figure 1B). On the other hand, the highest thickness of the posterior wall [299.34 $\pm 0.31 \mu \mathrm{m}]$ and the inter-ventricular septal wall $[204.93 \pm 1.12 \mu \mathrm{m}]$ was observed at the apex level (Figure 1E).

At the base level just beneath the left atrium, the cavity of LV appeared as a small triangle shaped opening that represents the aortic orifice (Figure 1B). A gradual widening of its cavity ranging from nearly triangular to rectangular shapes at the upper and lower mid levels (Figures 1C and 1D), and it became a small slit at the apex level (Figure 1E).

The cross section of the LV at base level revealed the branch of coronary artery, paraconal interventicular branch, in the lateral surface of LV wall (Figure 1B). Its position changed from



Figure 1. Mouse heart and its histological transverse sections according to $\mathrm{H} \& \mathrm{E}$ stain.

(A) Mouse heart under stereoscopic microscope. Mouse heart is divided into the atria (At) and the ventricles (Vt) with each level [B-E]. (B-E) Histological transverse sections of mouse ventricles. Panels B-E are corresponding to those of panel A. Base level shows a narrow small triangular shaped cavity of the aortic orifice (arrow head) [panel B, H\&E]. Upper mid level shows a moderately wide apparently triangular shaped cavity and relatively thick inter-ventricular septum [panel C, H\&E]. Lower mid level shows an irregular nearly rectangular shaped cavity [panel D, H\&E]. Apex level shows a slit like narrow cavity, relatively thin ventricular wall and apparently very thick inter-ventricular septum. Curved dashed arrows [panels B-D, H\&E] indicate the distance between the paraconal interventicular branch (c) and the apex of the anterior surface of left ventricle. Panel C: indicates the methodology for histoplanimetry. Briefly, blue lines crossing each other at right angle is used for the measurement of the thickness in the anterior wall $(\downarrow)$, posterior wall $(\uparrow)$, lateral ventricular wall $(\leftrightarrow)$, and interventricular septal wall (double $\leftrightarrow$ ). Asterisks denote the cavity of left ventricle. [H\&E, Bars: indicate $1 \mathrm{~mm}$ in panel A and $500 \mu \mathrm{m}$ in panels B-E].

lateral to anterior position at the mid levels (Figures 1C and 1D), meaning oblique running patterns of this artery towards the apex of heart.

\section{Histological characteristics of cardiac myofibers in mouse $L V$ at the base level}

Next, we compared the running pattern of cardiac myofibers in the lateral wall of LV at each level. The results were summarized in Table 2.

At the base level, the LV was composed of a thick wall (Figures 1B and 2A). The running directions of cardiac myofibers forming the lateral LV wall differed among sub-epicardial, intermediate, and sub-endocardial regions at the base level (Figures 2B and 2D). At both sub-epicardial and intermediate regions, most of cardiac myofibers showed a longitudinal running pattern, meaning they run along the axis between base and apex of heart (Figures 2B and 2C). However, at sub- 
Gouda et al. Journal of Histology \& Histopathology 2015,

http://www.hoajonline.com/journals/pdf/2055-091X-2-2.pdf

doi: 10.7243/2055-091X-2-2

Table 1. Statistical analysis of the thickness of the anterior, lateral, posterior ventricular wall and septal wall among the different levels of the left ventricle.

\begin{tabular}{lllll}
\hline Level & Anterior wall & Lateral ventricular wall & Posterior wall & Septal wall \\
\hline Base level & $383.68 \pm 0.29^{\mathrm{a}, \mathrm{b}, \mathrm{c}^{*}}$ & $112.36 \pm 0.55^{\mathrm{a}, \mathrm{c} \mathrm{d}^{*}}$ & $64.68 \pm 0.23^{\mathrm{a}, \mathrm{b}, \mathrm{c}^{*}}$ & $135.89 \pm 0.55^{\mathrm{b}, \mathrm{c}, \mathrm{d}^{*}}$ \\
Upper mid level & $269.98 \pm 0.41^{\mathrm{a}, \mathrm{b}, \mathrm{d}^{*}}$ & $189.03 \pm 0.58^{\mathrm{a}, \mathrm{b}, \mathrm{d}^{*}}$ & $90.63 \pm 0.22^{\mathrm{a}, \mathrm{b}, \mathrm{d}^{*}}$ & $193.69 \pm 1.03^{\mathrm{a}, \mathrm{b}, \mathrm{d}^{*}}$ \\
Lower mid level & $130.36 \pm 0.36^{\mathrm{a}, \mathrm{c}, \mathrm{d}^{*}}$ & $149.62 \pm 0.62^{\mathrm{a}, \mathrm{c}, \mathrm{d}^{*}}$ & $191.31 \pm 0.24^{\mathrm{a}, \mathrm{c}, \mathrm{d}^{*}}$ & $156.14 \pm 1.50^{\mathrm{a}, \mathrm{c}, \mathrm{d}^{*}}$ \\
Apex level & $89.45 \pm 0.78^{\mathrm{b}, \mathrm{d}, \mathrm{d}^{*}}$ & $93.32 \pm 1.35^{\mathrm{b}, \mathrm{d}, \mathrm{d}^{*}}$ & $299.34 \pm 0.31^{\mathrm{b}, \mathrm{d}, \mathrm{d}^{*}}$ & $204.93 \pm 1.12^{\mathrm{b}, \mathrm{c}, \mathrm{d}^{*}}$ \\
\hline
\end{tabular}

${ }^{*}$ Significant levels difference (Kruskal-Wallis test, $P<0.05$ ). a,b,c,d significant difference with apex, lower mid level, upper mid level and base, respectively (Scheffé's method, $P<0.05$ ).

Table 2. The running patterns of cardiac myofiber in lateral wall of mouse $\mathrm{LV}$ at different levels of the heart.

\begin{tabular}{llll}
\hline Levels regions & Sub-epicardial region & Intermediate region & Sub-endocardial region \\
\hline Base level & Longitudinal & Longitudinal & Circular \\
Upper mid level & Longitudinal to oblique & Oblique to circular & Longitudinal, circular \\
Lower mid level & Longitudinal and circular & circular & Longitudinal \\
Apex level & Longitudinal to oblique & Longitudinal & Longitudinal \\
\hline
\end{tabular}

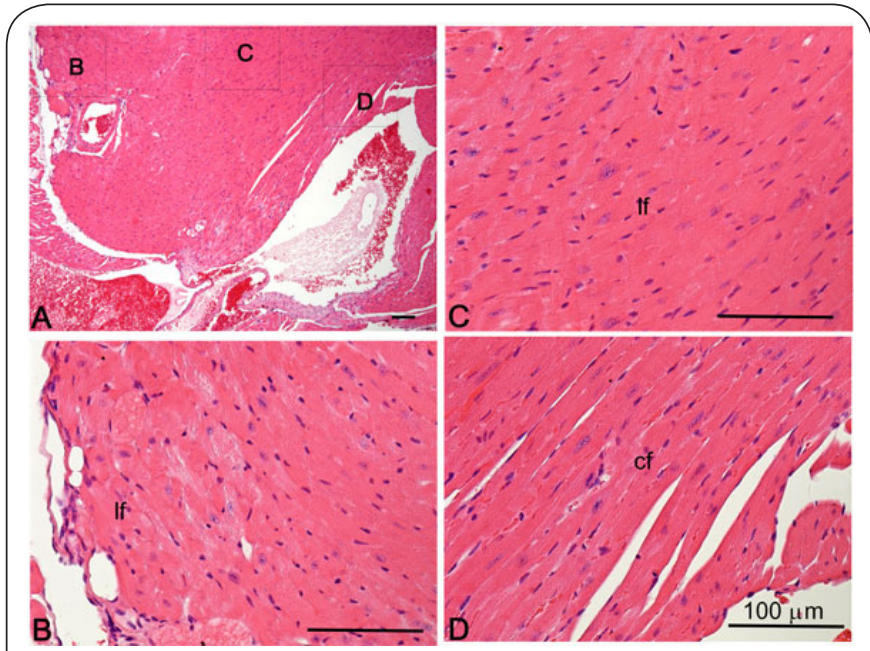

Figure 2. Photomicrographs of the cardiac myocytes in the base level of mouse LV according to H\&E stain.

(A-D) Notice thick compact wall of myocardium [panel A, $\mathrm{H} \& \mathrm{E}]$. Squares in panel $\mathbf{A}$ indicated the observed area in panels B-D. The cardiac myofibers in sub-epicardial region [panel B, H\&E] and in the intermediate region [panel C, $\mathrm{H} \& \mathrm{E}]$ of LV shows longitudinal running patterns (lf). At subendocardium [panel D, H\&E], they show circular running pattern (cf). [Bars: $100 \mathrm{~mm}$ ].

endocardial region, cardiac myofibers showed mainly a circular running pattern along the cavity of LV.

\section{Histological characteristics of cardiac myofibers in mouse $L V$ at the upper mid level}

At the upper mid level (Figure $3 \mathbf{A}$ ), the cardiac myofibers were longitudinally arranged along the axis between base and apex of

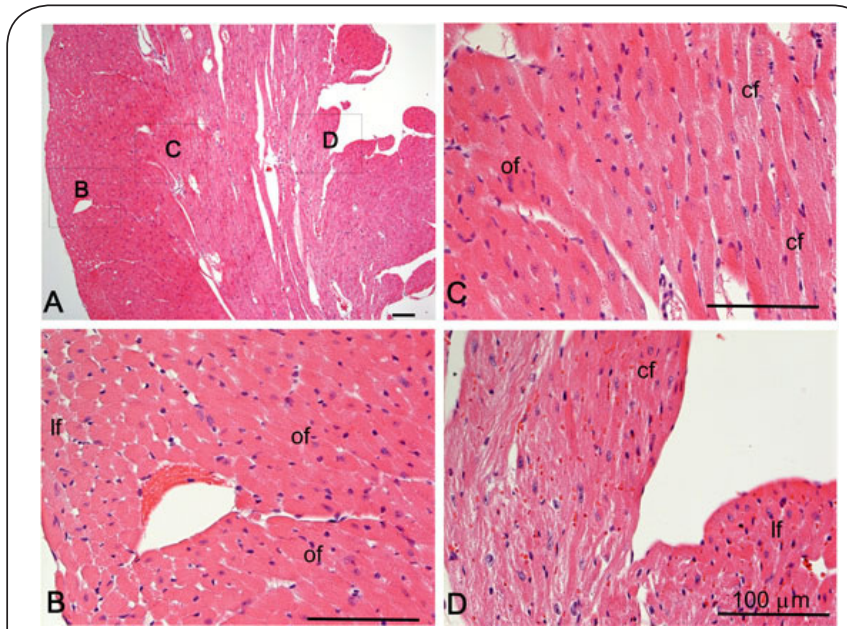

Figure 3. Photomicrographs of the cardiac myocytes in the upper mid level of mouse LV according to H\&E stain. (A-D) Squares in panel A indicate the observed areas in panels B-D. Notice packed sub-epicardial longitudinal myofibers (lf) and obliquely (of) arranged myofibers towards the intermediate myocardial region [panel $\mathbf{B}, \mathrm{H} \& \mathrm{E}]$. The intermediate myocardial [panel C, H\&E] showing both oblique (of) and circular arranged myofibers (cf). The myofibers at the sub-endocardium [panel $\mathbf{D}, \mathrm{H} \& \mathrm{E}$ ] showing two running patterns longitudinal (lf) and circular (cf). [H\&E, Bars: $100 \mathrm{~mm}$ ].

the heart at sub-epicardial region in lateral wall of LV (Figure 3B). They changed to oblique running patterns at the deep portion of sub-epicardial regions, indicating a spiral running pattern of them along the axis between base and apex of the heart. And then, cardiac myofibers changed from an oblique to circular running patterns towards deep intermediate regions 
(Figures 3B and 3C). At the sub-endocardial region, cardiac myofibers showed both longitudinal and circular running patterns (Figure 3D).

\section{Histological characteristics of cardiac myofibers in mouse LV at the lower mid level}

At the lower mid level (Figure 4A), the cardiac myofibers showed both longitudinal and circular running patterns along the axis between base and apex of the heart at the sub-epicardial region (Figure 4B). At the intermediate region, cardiac myofibers predominantly showed circular running patterns (Figure 4C). At the sub-endocardial region, cardiac myofibers were longitudinally arranged (Figure 4D).

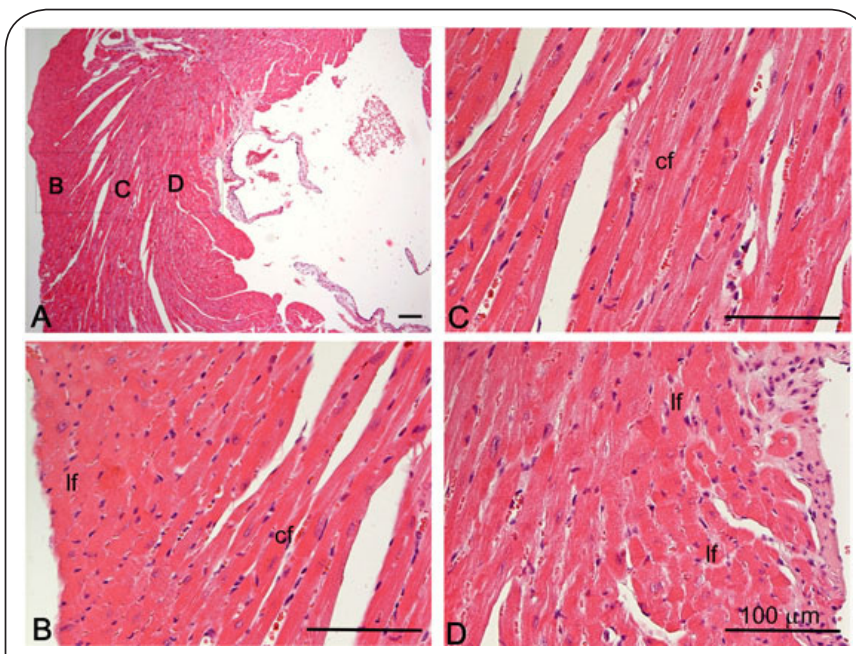

Figure 4. Photomicrographs of the cardiac myocytes in the lower mid level of mouse $\mathrm{LV}$ according to H\&E stain. (A-D) Squares in panel A, H\&E indicate the observed areas in panels B-D. Notice a higher magnification of the subepicardial region [panel B, H\&E], showing longitudinally arranged fibers (lf) that transformed into circular fibers (cf). Higher magnification of the intermediate myocardial region [panel $\mathbf{C}, \mathrm{H} \& \mathrm{E}$ ], showing circularly arranged (cf) bundles of cardiomyocytes. Higher magnification of the subendocardial region [panel D H\&E], showing longitudinally arranged (lf) fibers. Bars: $100 \mu \mathrm{m}$.

\section{Histological characteristics of cardiac myofibers in mouse $L V$ at apex level}

At the apex level (Figure 5A), the cardiac myofibers were arranged longitudinally beneath the epicardium and obliquely at intermediate region along the axis between base and apex of the heart (Figure 5B). Then most of cardiac myofibers were circularly arranged at the intermediate myocardial region (Figures 5B and 5C). At the sub-endocardial region, cardiac myofibers were longitudinally arranged (Figure 5D).

\section{MT stained sections}

\section{Connective tissues in the mouse LV}

We examined the amount of connective tissues by MT stained

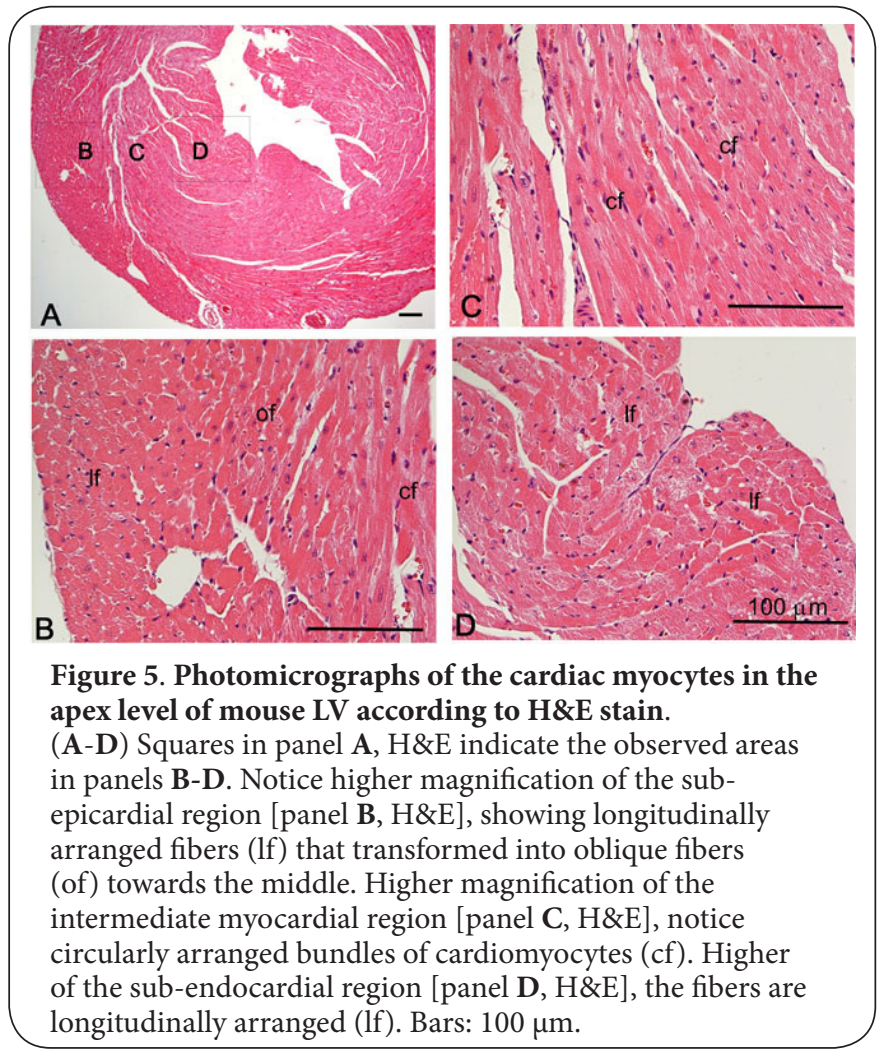

sections at each level and revealed that there was a very little amount of collagen fibers just around each individual cardiac myocyte (Figures 6A-C). They were observed around the long axis of cardiac myocytes (Figures $\mathbf{6 B}$ and $\mathbf{6 C}$ ), and there was no difference in the amount of connective tissues among different levels [data not shown].

\section{Discussion}

The cardiac myocytes architecture in LV is complex. Their arrangement is as so critical as evidenced by a significant functional impairment seen in post-infarction remodeling and other cardiac diseases. Adequate understanding of the myocardial structure and function is indispensable for the management of patients with congenital and acquired heart diseases [12]. In mice, the cardiac myofibers are longer [ 150 $\mu \mathrm{m}]$ than the thickness of the standard histological sections [13], thus in the present study, we applied step-serial cross sections of the LV but not longitudinal sections. Furthermore, the mouse was chosen because it is the most popular animal model for studying normal and abnormal cardiac development as it has a strong heart [600 beats/min] [14].

In the present study, we revealed changes in the thickness of $L V$ wall and the shape of its cavity among studied levels. It had been reported that the thickest part of cardiac muscular strand is at the basal level of human LV [15]; however, this study showed that the thickest part of the lateral LV wall was observed at the upper mid level. Towards the apical 

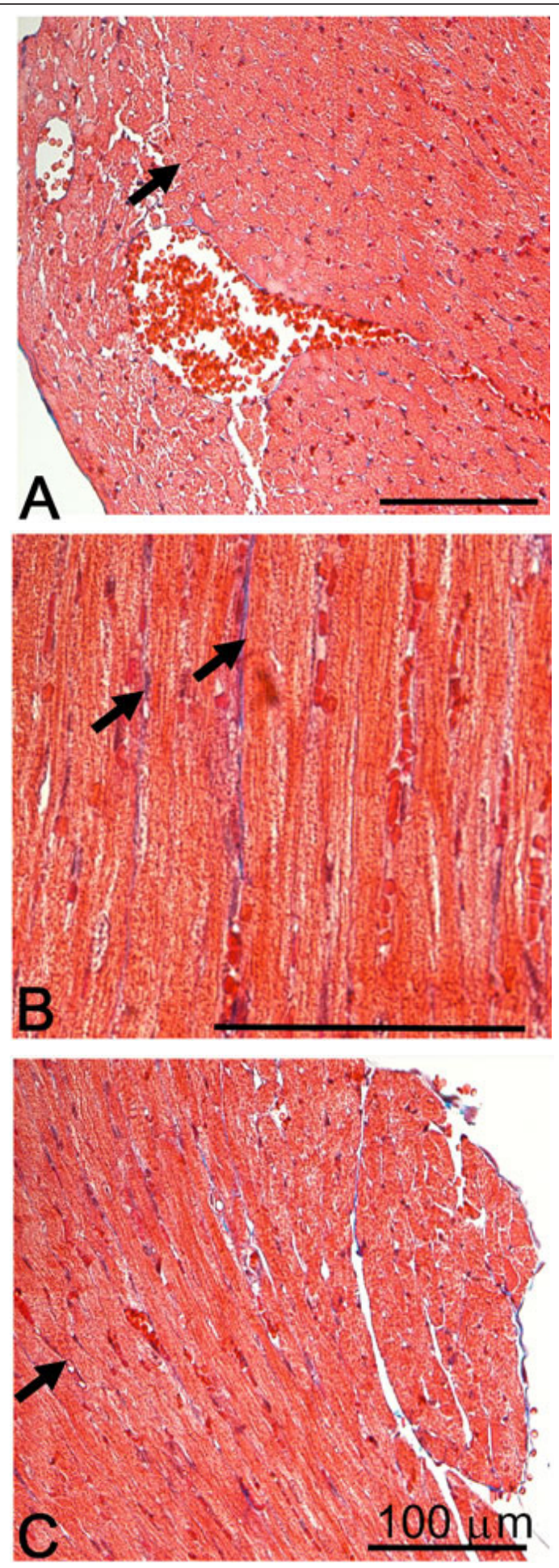

Figure 6. Photomicrographs of the connective tissue in the base level of mouse $\mathrm{LV}$ according to MT stained sections (A-C).

Notice few collagen fibers (arrows) surrounding individual cardiac myocyte in the sub-epicardial region [panel A, MT], intermediate region [panel $\mathbf{B}$, $\mathrm{MT}$ ], and in the sub-endocardial region [panel C, MT]. Bars: $100 \mu \mathrm{m}$. cone, the lateral LV wall became thinner, while the interventricular septum became thicker than that in other levels. Similar features were recorded in bovine heart $[16,17]$. These differences might reflect the functional or developmental species-related differences of heart structure. Furthermore, the changes of the thickness of LV wall observed in this study were in accordance with the previous report by [18] who referred these changes to the presence of papillary muscles and trabeculae. These structural changes were due to the continuous cardiac myocytes loops forming the LV walls [13].

The present work revealed obvious complexity of cardiac myofibers architecture in-between different levels, as well as, within the same level of LV. These identified features in the present study were also observed in human heart [13]. Characteristically, the cardiac myofibers just beneath of epicardium showed mainly a longitudinal running pattern along with the axis between base and apex of the LV, and they tended to be changed into a longitudinal or circular running pattern towards endocardium at all examined LV levels. Using diffusion tensor magnetic resonance imaging, at the ventricular epicardium, the fibers were extending obliquely [2].

The different orientations of cardiac myofibers throughout the $L V$ wall at the same level might indicate the helical looping of cardiac myofibers forming the LV as mainly suggested by Torrent-Guasp [19,1]. In addition, our considerations might be also supported the previous report of other researchers [20]. They observed highly discontinuous laminae of myofibers that begin and end many times in-between the endocardium and the epicardium.

Furthermore, the running pattern of cardiac muscle is closely related to the blood vessels of the heart $[21,22]$. In fact, the left paraconal interventicular branch in the present study run obliquely. Moreover, some studies reported that there is a correlation between the spiral running pattern of cardiac myofibers and the ventricular function [augmentation the momenta of the blood flow] $[23,24]$.

The cardiac vasculature might not necessarily correspond to the direction of the cardiac myofibers. By using two photons microtomy, the cardiac blood vessels were shown to move up, while the cardiac myofibers generally were moved down [13]. The spiral orientation of sub-epicardial myofibers to form the double helical muscular band in LV had been recorded anatomically [25]. Many congenital heart defects such as ventriculo-arterial discordance (complete transposition of the great arteries], encouraged the interruption of the spiral pattern of the heart [26]. In the upper mid level sections, the diverse running patterns of cardiac myofibers noted in the sub-epicardial, intermediate, and endocardial region, were in agreement with [27]. They showed that, this peculiar arrangement of cardiomyocytes and twisting appearance are considered the key factor of normal systolic and diastolic myocardial function.

In this study, the little amount of connective tissue observed 
around each cardiomyocyte was in accordance with [7]. They mentioned that each individual cardiac myocyte is wrapped in an endomysium, which supports the intercalated discs in binding adjacent myocyte to one another, as well as forming a so-called 'weave' around the myocytes. However, another study attributed the separated and distinguishable myofibers to the difference in the fiber direction within their boundaries as the fibers are not outlined by a major connective tissue sheet [7]. They depicted this complex nested continuum of LV wall to form mechanical and electrical syncytium. Moreover, contraction of the ventricular myocardial band in this way creates a muscular force for suction to fill the ventricle during diastole [6]. Other researchers also suggested that the oblique oriented fibers of the septal wall are necessary for functional performance of LV [16]. Our results might emphasize the close correlation between histology and function of mouse LV.

\section{Conclusion}

In this study, we revealed obvious changes in LV wall thickness, inter-ventricular septum thickness, and also in its cavity shape from its base to apex in mouse heart. Furthermore, we revealed the running pattern of cardiac myofibers in LV wall at different levels from beneath atrium to apex of the heart with several histological characteristics. The different running patterns of the cardiac myofibers among different levels as well as, within the same level from sub-epicardial to the endocardial region might indicate multiple rolling of the cardiac myofibers. Thus, we suggested that the band model of Torrent-Guasp (Figure 7) accounts for the patterns observed in mouse LV. With the new cardiac imaging techniques, the general arrangement of the myofibers that make up the left ventricular walls is reviewed to provide a morphologic basis

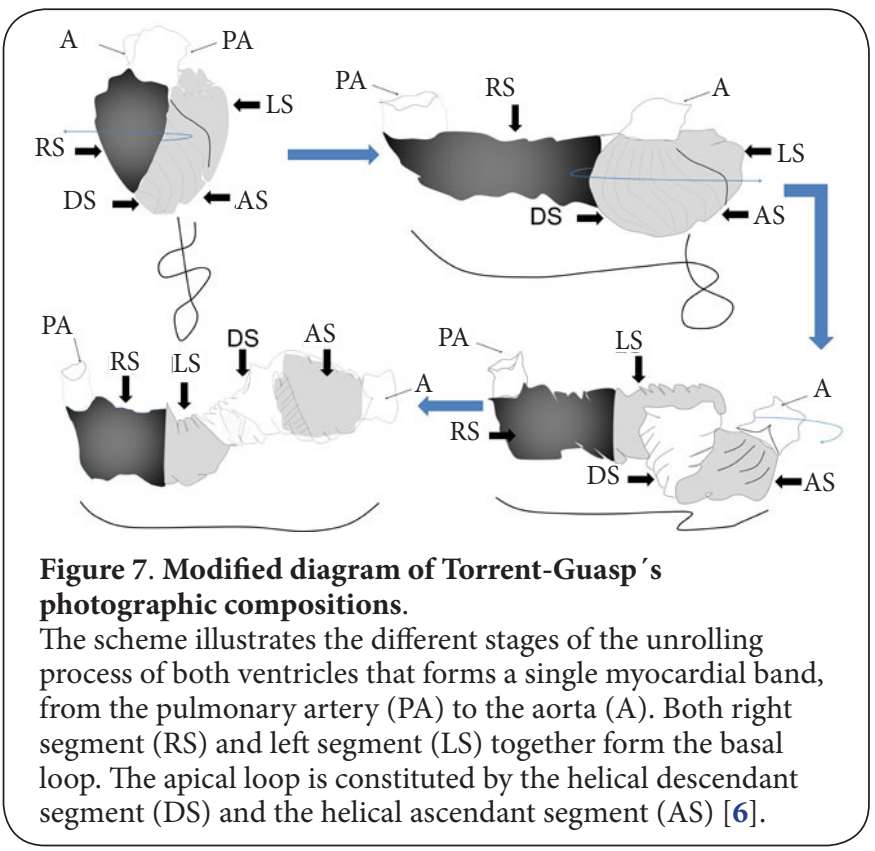

for diagnosis of several cardiac pathologies such as cardiac deformation, failure and myopathy. In addition, disarray of LV myocardial fibers could be a predictor of chronic kidney disease. However, further investigations are needed to concern both the orientation and coupling of cardiac fibers throughout all levels of the LV to strengthen the present data in the literature.

\section{Competing interests}

The authors declare that they have no competing interests.

Authors' contributions

\begin{tabular}{|l|c|c|c|}
\hline Authors' contributions & ZAG & YHAE & AOS \\
\hline Research concept and design & $\checkmark$ & -- & -- \\
\hline Collection and/or assembly of data & $\checkmark$ & -- & -- \\
\hline Data analysis and interpretation & $\checkmark$ & $\checkmark$ & $\checkmark$ \\
\hline Writing the article & $\checkmark$ & $\checkmark$ & $\checkmark$ \\
\hline Critical revision of the article & $\checkmark$ & $\checkmark$ & $\checkmark$ \\
\hline Final approval of article & $\checkmark$ & $\checkmark$ & $\checkmark$ \\
\hline Design of figures & -- & $\checkmark$ & $\checkmark$ \\
\hline Statistical analysis & -- & $\checkmark$ & -- \\
\hline
\end{tabular}

Acknowledgement

We would like to thank Dr Michael Henshaw, Assistant professor for English Leading programs, Graduate School of Veterinary Medicine, Hokkaido University, Japan for his English language editing and reviewing of the manuscript.

\section{Publication history}

EIC: Giuseppe Musumeci, University of Catania, Italy.

Received: 05-Dec-2014 Final Revised: 25-Dec-2014

Accepted: 27-Dec-2014 Published: 21-Jan-2015

\section{References}

1. Torrent-Guasp F, Kocica MJ, Corno AF, Komeda M, Carreras-Costa F, Flotats A, Cosin-Aguillar J and Wen H. Towards new understanding of the heart structure and function. Eur J Cardiothorac Surg. 2005; 27:191-201. | Article | PubMed

2. Deng $D$, Jiao $P, Y e X$ and $X i a ~ L$. An image-based model of the whole human heart with detailed anatomical structure and fiber orientation. Comput Math Methods Med. 2012; 2012:891070. | Article | PubMed Abstract | PubMed Full Text

3. Sengupta PP, Krishnamoorthy VK, Korinek J, Narula J, Vannan MA, Lester SJ, Tajik JA, Seward JB, Khandheria BK and Belohlavek M. Left ventricular form and function revisited: applied translational science to cardiovascular ultrasound imaging. J Am Soc Echocardiogr. 2007; 20:53951. | Article | PubMed Abstract | PubMed Full Text

4. Streeter Jr DD. Gross morphology and fiber geometry of the heart. In: Berne RM Sperelakis N Geiger SR [editors]. Handbook of physiology section 2. The Heart [American Physiology Society]. Williams \& Wilkins: Baltimore. 1979; 1:61-112.

5. Greenbaum RA, Ho SY, Gibson DG et al. Left ventricular fiber architecture in man. Br Heart J. 1981, 45; 248-263.

6. Torrent-Guasp F, Kocica MJ, Corno A, Komeda M, Cox J, Flotats A, Ballester-Rodes $\mathrm{M}$ and Carreras-Costa F. Systolic ventricular filling. Eur J Cardiothorac Surg. 2004; 25:376-86. | Article | PubMed

7. Anderson RH, Ho SY, Redmann K, Sanchez-Quintana D and Lunkenheimer PP. The anatomical arrangement of the myocardial cells making up the ventricular mass. Eur J Cardiothorac Surg. 2005; 28:517-25. | Article | PubMed

8. Pope AJ, Sands GB, Smaill BH and LeGrice IJ. Three-dimensional transmural organization of perimysial collagen in the heart. Am J Physiol 
Gouda et al. Journal of Histology \& Histopathology 2015,

http://www.hoajonline.com/journals/pdf/2055-091X-2-2.pdf

doi: $10.7243 / 2055-091 X-2-2$

Heart Circ Physiol. 2008; 295:H1243-H1252. | Article | PubMed Abstract I PubMed Full Text

9. Zhang C, Cheng YJ, Chen J, Wickline S and Wang LV. Label-free photoacoustic microscopy of myocardial sheet architecture. J Biomed Opt. 2012; 17:060506. | Article | PubMed Abstract | PubMed Full Text

10. Criscione JC, Rodriguez F and Miller DC. The myocardial band: simplicity can be a weakness. Eur J Cardiothorac Surg. 2005; 28:363-4. | Article | PubMed

11. Bancroft JD and Layton C. The Hematoxylin and eosin. In: Suvarna SK, Layton C and Bancroft JD editors. Theory and Practice of histological techniques. $7^{\text {th }}$ ed., Churchill Livingstone of El Sevier. Philadelphia. Ch 10 and 11. 2013; 172-214.

12. Corno AF, Kocica MJ, Chappory LA et al. Inter-ventricular septum: New observations on the structure and function coupling. Basic Applied Myology. 2009; 19:41-48. | Pdf

13. Huang H, Macgillivray C, Kwon HS, Lammerding J, Robbins J, Lee RT and So $P$. Three-dimensional cardiac architecture determined by two-photon microtomy. J Biomed Opt. 2009; 14:044029. | Article | PubMed Abstract I PubMed Full Text

14. Zaragoza C, Gomez-Guerrero C, Martin-Ventura JL, Blanco-Colio L, Lavin B, Mallavia B, Tarin C, Mas S, Ortiz A and Egido J. Animal models of cardiovascular diseases. J Biomed Biotechnol. 2011; 2011:497841. | Article | PubMed Abstract | PubMed Full Text

15. Torrent-Guasp F. [Structure and function of the heart]. Rev Esp Cardiol. 1998; 51:91-102. | PubMed

16. Corno AF, Kocica MJ and Torrent-Guasp F. The helical ventricular myocardial band of Torrent-Guasp: potential implications in congenital heart defects. Eur J Cardiothorac Surg. 2006; 29 Suppl 1:S61-8. | Article I PubMed

17. Hayabuchi Y, Sakata M and Kagami S. Assessment of the Helical Ventricular Myocardial Band Using Standard Echocardiography. Echocardiography. 2014. | Article | PubMed

18. Bogaert J and Rademakers FE. Regional nonuniformity of normal adult human left ventricle. Am J Physiol Heart Circ Physiol. 2001; 280:H610-20. | Article | PubMed

19. Sedmera D, Pexieder T, Vuillemin M, Thompson RP and Anderson RH. Developmental patterning of the myocardium. Anat Rec. 2000; 258:31937. I PubMed

20. Harrington KB, Rodriguez F, Cheng A, Langer F, Ashikaga H, Daughters GT, Criscione JC, Ingels NB and Miller DC. Direct measurement of transmural laminar architecture in the anterolateral wall of the ovine left ventricle: new implications for wall thickening mechanics. Am J Physiol Heart Circ Physiol. 2005; 288:H1324-30. | Article | PubMed Abstract | PubMed Full Text

21. Sanchez-Quintana D, Anderson RH and Ho SY. Ventricular myoarchitecture in tetralogy of Fallot. Heart. 1996; 76:280-6. | Article | PubMed Abstract | PubMed Full Text

22. Buckberg GD. The structure and function of the helical heart and its buttress wrapping. II. Interface between unfolded myocardial band and evolution of primitive heart. Semin Thorac Cardiovasc Surg. 2001; 13:320-32. | Article | PubMed

23. Stonebridge $P A$ and Brophy $C M$. Spiral laminar flow in arteries? Lancet. 1991; 338:1360-1. | Article | PubMed

24. Marinelli R, Penney DG, Marinelli WA et al. Rotary motion in the heart and blood vessels: a review. Journal of Applied Cardiology. 1991; 6: 421-431.

25. Torrent-Guasp F, Buckberg GD, Clemente C, Cox JL, Coghlan HC and Gharib $M$. The structure and function of the helical heart and its buttress wrapping. I. The normal macroscopic structure of the heart. Semin Thorac Cardiovasc Surg. 2001; 13:301-19. | Article | PubMed

26. Kirby ML. Embryogenesis of transposition of the great arteries: a lesson from the heart. Circ Res. 2002; 91:87-9. | Article | PubMed

27. Ingels NB, Jr., Hansen DE, Daughters GT, 2nd, Stinson EB, Alderman EL and Miller DC. Relation between longitudinal, circumferential, and oblique shortening and torsional deformation in the left ventricle of the transplanted human heart. Circ Res. 1989; 64:915-27. | Article | PubMed
Citation:

Gouda ZA, Elewa YHA and Selim AO. Histological architecture of cardiac myofibers composing the left ventricle of murine heart. J Histol Histopathol. 2015; 2:2. http://dx.doi.org/10.7243/2055-091X-2-2 